\title{
Numerical study of fracture arrest on snow cover
}

\author{
B. M. Chiaia, B. Frigo \\ Politecnico di Torino, Department of Structural and Geotechnical Engineering, \\ Corso Duca degli Abruzzi, 24, 10129 Torino, Italy \\ barbara.frigo@polito.it
}

\begin{abstract}
Under the hypothesis of a perfectly brittle phenomenon, avalanche triggering can be investigated numerically by means of Linear Elastic Fracture Mechanics (LEFM). Since, however, the real phenomenon is intrinsically dynamical, another aspect to investigate is represented by dynamic fracture propagation. In this paper, we model dynamic crack propagation into a dry snow slab and we investigate the possibility to arrest the crack propagation through the presence of weak zones distributed along the extension of the snow slope. Assuming that the weak layer is almost collapsed, we simulate the efficiency of artificial voids in the slab to arrest fracture propagation, into the framework of Dynamical Fracture Mechanics. We put forward here a new philosophy for the use of artificial discontinuities (void) into the snowpack able to perform as crack arresters distributed along the snow slope area: the target is to split a large avalanche slab into smaller slabs, causing small avalanches to propagate with less catastrophic effects.
\end{abstract}

KEYWORDS. Fracture mechanics; Snow avalanche; Crack arresters; Active protection.

\section{INTRODUCTION}

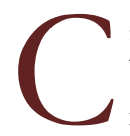

aused by the snow stratifications, the snowpack can be schematized as a sandwich structure: a thin weak layer between a thick, strong and stiff slab and cohesive basal layer. The slab avalanche release pursuits a sequence of mechanisms: it starts with fracture at the weak layer on the bed surface (Mode II) following by fracture at the crown (Mode I), fracture at the flanks (Mode II and Mode III) and fracture at the stauchwall (crushing). Under the hypothesis of a perfectly brittle phenomenon, avalanche triggering is usually investigated numerically by means of Linear Elastic Fracture Mechanics [1,2]. Since, however, the real phenomenon is intrinsically dynamical, another aspect to investigate is represented by dynamic fracture propagation. In the framework of Fracture Mechanics, the paper analyses the second mechanism of dry slab avalanches trigging: the fracture at the crown. As a consequence of the first triggering mechanism (Mode II fracture propagation between weak layer and snow slab), the secondary Mode I crack propagation is studied by means a numerical simulations to analyse its possible arrest based on Dynamic Elastic Fracture Mechanics and on the theory of crack arresters.

The snowpack is considered like a linear-elastic plate (2D problem) with physical parameters chosen according to the literature. By taking into account kinetic energy and thanks to the use of the FEM software FRANC 2D [3], several paths of crown fracture propagation and their stability have been investigated in continuous (natural) snow cover.

Considering the spatial variability of the physical and mechanical properties of snow cover, some studies have suggested that increasing its spatial variability would lead to lower release probability for snow avalanches. Although the studies have very different approaches, such as cellular automata [4] and statistical mechanics [5] models, the idea that increased variability causes lower probability for catastrophic avalanches is the same. To support this perception, the paper investigates the possible reduction of the propagation of crown fracture by the theory of Crack Arresters applied on the 
snow cover. Dynamic crack propagation into a dry snow slab is modelled to assess the possibility of crack arrest through the presence of discontinuous weak zones (equipped with different shapes and geometries of artificial voids) distributed along the extension of the snow slope.

The use of crack arresters is a first step towards a new idea of active avalanche protection: the target is to split a large avalanche slab into smaller slabs, causing small avalanches to propagate with less catastrophic effects thanks to artificial discontinuities (void) into the snowpack - the snow crack arresters- distributed along the snow slope release area.

\section{THE PRINCIPLE OF CRACK ARREST}

W speed.

hen the driving force $G$ for crack extension exceeds the material crack resistance $R$, the structure is unstable, and rapid crack propagation occurs (Fig. 1.a). According to the first law of thermodynamics, the excess energy (shaded area in Fig. 1a) is converted into kinetic energy. The magnitude of the kinetic energy dictates the crack

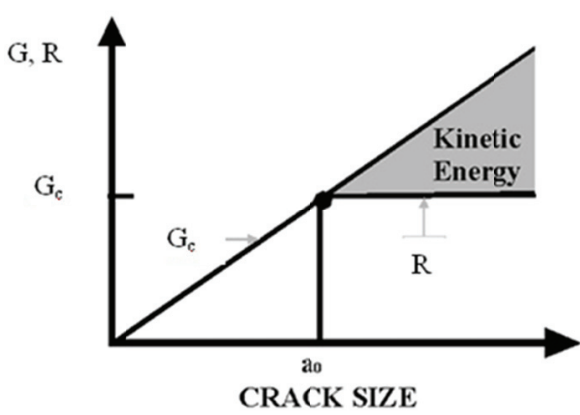

(a)

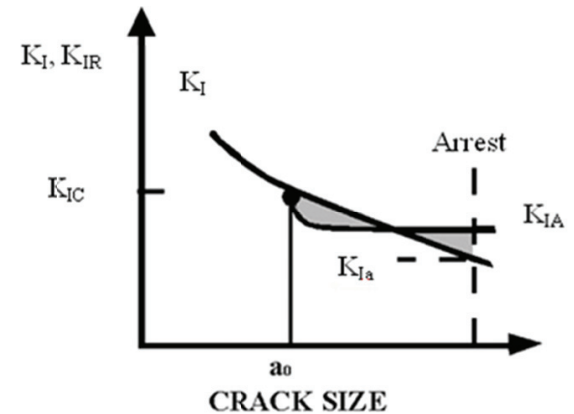

(b)

Figure 1: Balance of energy for: (a) fracture propagation, (b) unstable crack propagation and arrest (Anderson, 1995).

In a quasi-static case, a crack is stable if the driving force $G$ is less than or equal to the material resistance R. Similarly, if the energy available for an incremental extension of a rapidly propagating crack falls below the material resistance, the crack arrests. Fig. $1 \mathrm{~b}$ illustrates a simple crack arrest. The fracture initiates when $\mathrm{K}_{\mathrm{I}}=\mathrm{K}_{\mathrm{Ic}}$. If the structure has a falling $G$ curve, it eventually crosses the $\mathrm{R}$ curve. Arrest does not occur at this point, because the structure still contains kinetic energy that can be converted into fracture energy. Arrest occurs below the resistance curve, after most of the available energy has been dissipated. The apparent arrest toughness, $\mathrm{K}_{\mathrm{I}}$, is therefore less than the true material resistance, $\mathrm{K}_{\mathrm{IA}}$. The difference between $K_{I a}$ and $K_{I A}$ is governed by the kinetic energy created during crack propagation; $K_{\text {IA }}$ is a material property, whereas $\mathrm{K}_{\mathrm{Ia}}$ depends on geometry. Figs. 1a and $1 \mathrm{~b}$ compare material resistance with quasi-static driving force curves representing $\mathrm{K}_{\mathrm{I}}$ and $G$ values. If the crack driving force incorporates the effect of kinetic energy, the Griffith-Irwin energy balance must be modified to include kinetic energy, so, the dynamic definition of energy release rate is [6]:

$$
G(t)=\frac{d F}{d A}-\frac{d U}{d A}-\frac{d E_{k}}{d A}
$$

where, as usual, $F$ is the work done by external forces, $A$ is the fracture surface area, $U$ is the elastic deformation energy and $E_{k}$ is the kinetic energy.

Considering the stage of crown fracture, the governing equation for Mode I crack propagation under elasto-dynamic conditions can be written as:

$$
K_{I}(t)=K_{I D}(v)
$$

where $v$ is the crack speed, $\mathrm{K}_{\mathrm{I}}$ the instantaneous stress intensity factor and $\mathrm{K}_{\mathrm{ID}}$ is the material resistance to crack propagation (dynamic crack-resistance), which depends on the crack velocity and can be measured as a function of the crack speed by means of optical methods.

For an infinite body or short propagation periods, $\mathrm{K}_{\mathrm{I}}(\mathrm{t})$ is not equal to the static stress intensity factor. The dynamic stress intensity factor and the dynamic energy release rate can be expressed in the form:

$$
K_{I}(t)=k(v) K_{I}(0)
$$




$$
G(t)=g(v) G(0)
$$

where $\mathrm{K}_{\mathrm{I}}(0)$ and $G(0)$ are the static stress intensity factor and the energy release rate, respectively, $g$ and $k$ are universal functions of crack speed $v$. Eq. 3.a is valid as long as the length of crack propagation is small compared to specimen dimensions. Since $G=\mathrm{K}^{2} / \mathrm{E}$, it is possible to combine Eqns. 3.a and 3.b, obtaining the relationship between $\mathrm{K}_{\mathrm{I}}$ and $G$ in the form:

$$
G(t)=A(v) \frac{K_{I}^{2}(t)}{E}
$$

where :

$$
A(v) \approx\left[\left(1-\frac{v}{c_{r}}\right)(1-h v)\right]^{-1}
$$

With the same approach and assuming the arrest of fracture propagation, Jamieson and Johnston [7] derive the expression of width of dry slab avalanche depending on slab parameters (slab thickness, slab tensile strength and basal shear strength).

\section{NUMERICAL SIMULATION OF DYNAMIC FRACTURE ARREST IN DRY SNOW AVALANCHES}

C

rack arrest can be attained in three different ways: reduction of the crack tip stress intensity, reduction of the stress concentration and introduction of residual compressive stresses [8]. In the case of snow avalanches, the possibility is to reduce the stress intensity factor by forcing the crack to runs into a weaker part of the snowpack. Considering some experimental results for riveted sheet structures, we know that if stringers are attached to the plate, it is even advantageous that the crack passes between rivet holes: the stringer takes load from the cracked skin and thus reduces the stress intensity factor. The stringer is more effective in doing so when the rivets are closer to the crack: the stiff stringer element between the two closest rivets tends to keep the crack closed. If the crack passes between two holes the nearest rivets are very close to the crack. Then the stringer is very effective in the reduction of crack tip stresses. Since the beneficial effect of a single hole itself is negligible, the best results are obtained when the crack passes between a certain geometrical arrangement of holes.

With the use of the FEM software FRANC 2D [3], based on the maximum circumferential stress criterion for fracture propagation, several paths of crown fracture propagation and their stability have been investigated. The snow cover is

\begin{tabular}{|c|c|c|c|}
\hline Parameter & Typical value & Range & Reference \\
\hline Slope angle: $\alpha$ & $38^{\circ}$ & $30-45^{\circ}$ & {$[9]$} \\
\hline Snow slab height: $H$ & $0.5 \mathrm{~m}$ & $0.3-1 \mathrm{~m}$ & {$[9]$} \\
\hline Weak layer height: $h$ & $10 \mathrm{~mm}$ & $1-15 \mathrm{~mm}$ & [9] \\
\hline Snow slab density: $\varrho$ & $200 \mathrm{~kg} \mathrm{~m}^{-3}$ & $100-300 \mathrm{~kg} \mathrm{~m}^{-3}$ & {$[9]$} \\
\hline $\begin{array}{l}\text { Snow slab elastic modulus: } \\
\qquad E\end{array}$ & $1 \mathrm{MPa}$ & $0.5-10 \mathrm{MPa}$ & {$[9]$} \\
\hline Snow slab Poisson's ratio: $\nu$ & 0.2 & $0.1-0.4$ & {$[9]$} \\
\hline $\begin{array}{l}\text { Weak layer shear modulus: } \\
G_{\mathrm{w}}\end{array}$ & $0.1 \mathrm{MPa}$ & $0.1-0.6 \mathrm{MPa}$ & {$[10,11]$} \\
\hline Weak layer peak strength: $\tau_{p}$ & $2 \mathrm{kPa}$ & $0.3-6 \mathrm{kPa}$ & {$[10,11]$} \\
\hline $\begin{array}{l}\text { Mode II fracture energy: } G \\
\text { IIc }\end{array}$ & $0.2 \mathrm{~J} \mathrm{~m}^{-2}$ & $0.1-0.3 \mathrm{~J} \mathrm{~m}^{-2}$ & {$[12]$} \\
\hline
\end{tabular}
considered like a linear-elastic square sheet $(100 \mathrm{~m} \times 100 \mathrm{~m})$, with unit thickness $(1 \mathrm{~m})$, and with physical parameters chosen according to Tab. 1 [2].

Table 1: Typical values for snow slab and weak layer [2]. 
For simplicity, the conditions of no horizontal displacement at the lateral sides of the slab, and of no vertical displacement at the top of the slab, have been considered. An initial flaw was imposed at one lateral side of the slab. The absence of cohesive behaviour has been considered in the simulations, and the dynamic values of the fracture parameters have been adopted (see Eqns. 1 - 5).

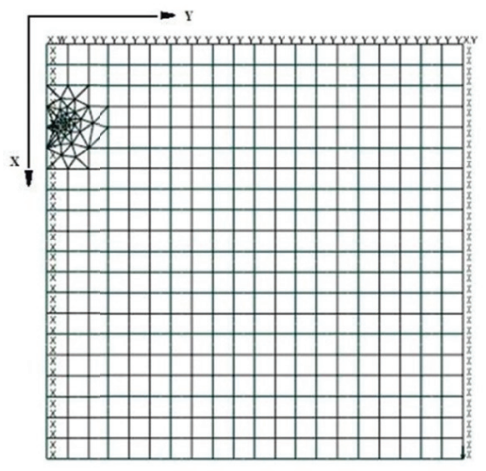

(a)

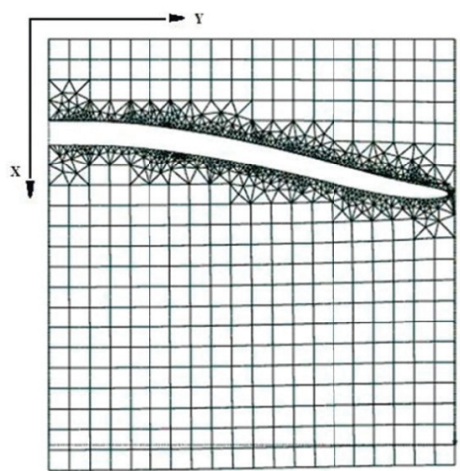

(b)

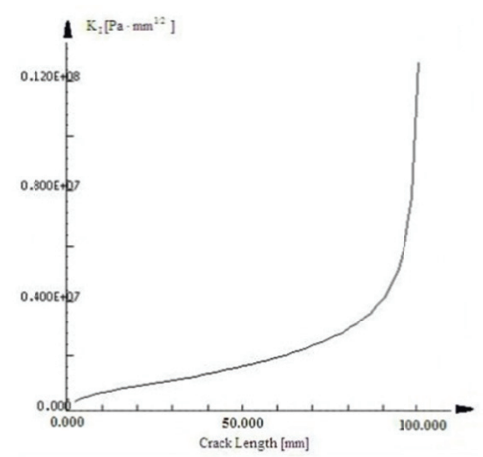

(c)

Figure 2: (a) Scheme of snowpack with induced initial flaw on the left border.

(b) Crown fracture propagation on the snowpack. (c) Plot of $K_{I D}$ vs. crack length.

As a preliminary test, a simulation of the slab without crack arresters was carried out. Crown fracture propagates initially in the horizontal direction and then rotates slightly. The $\mathrm{K}_{\mathrm{I}}$ value, depending on the fracture growth, increases monotonically indicating unstable fracture propagation (Fig. 2).

Several simulations have been conducted afterwards to study the influence of different starting position of the initial flaw and different arrangements of crack arresters in the snow cover. About the latter, we tested different geometries of crack arresters: for example a continuous single linear crack arrester (with width and length equal to : $2 \mathrm{~m} \times 5 \mathrm{~m}$ and $0.1 \mathrm{~m} \times 5 \mathrm{~m}$ ), or a single and parallel discontinuous linear crack arresters. In all these simulations, the crack overpasses the voids without stopping and cancelling the presence and the effects of the crack arresters.

The first interesting result is obtained analysing the plot of Stress Intensity Factor vs. Crack length in the case of parallel discontinuous linear crack arresters (Fig. 3). We note a little drop of the $K_{I D}$ which indentifies a temporary stop of the fracture when the crack overpasses the snowpack between two parallel rows of discontinuous crack arresters: the spatial influence of crack arrester is not enough and the fracture restarts its propagation.

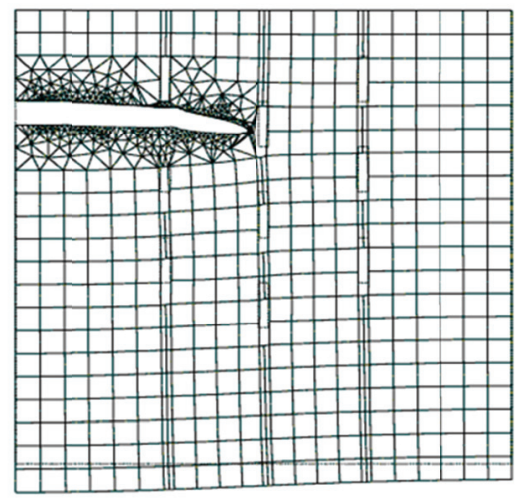

(a)

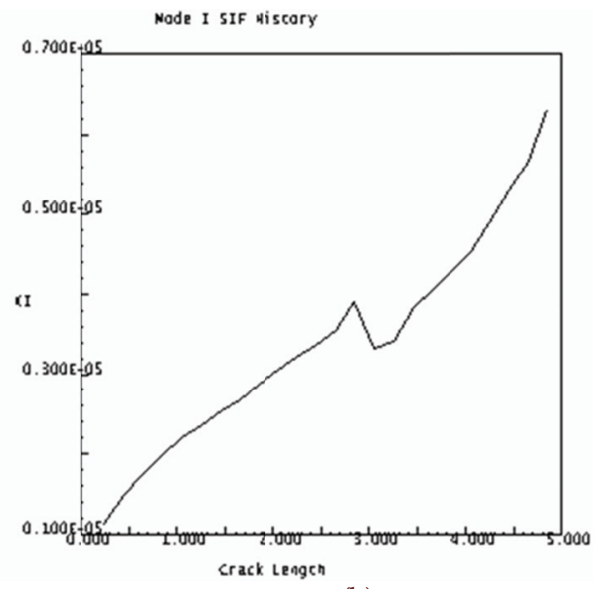

(b)

Figure 3: (a) Crown fracture propagation on the snowpack with parallel discontinuous linear crack arresters; (b) Plot of KID vs. crack length.

The optimal condition (i.e. a sharp decrease of $\mathrm{K}_{\mathrm{I}}$, see Fig. $4 \mathrm{~b}$ ), was obtained for a quincuncial crack arrester configuration (Fig. 4a). In a model slab $(100 \mathrm{~m} \times 100 \mathrm{~m})$ with a central area $(30 \mathrm{~m} \times 40 \mathrm{~m})$ weakened by the presence of a quincuncial 
arrangement of circular or hexagonal arresters (holes with radius equal to $3 \mathrm{~m}$ ), fracture propagation in the snow cover was totally interrupted. Note the transition from unstable fracture condition to a stable one, with crack arrest that occurs between the first and the second vertical column of holes (Figs. $4 \mathrm{a}$ and $4 \mathrm{~b}$ ).

Fig. $5 \mathrm{a}$ and $5 \mathrm{~b}$ show that, varying the positions of the initial crack, the simulations give similar results: each crack arrester creates a "influence area" (whose radius, in our simulations, can be estimated as being approximately twice the hole radius) which avoids the coalescence of the crack tip within the hole. After a minimum point (B), the $K_{I}$ factor increases again until another influence area is reached.

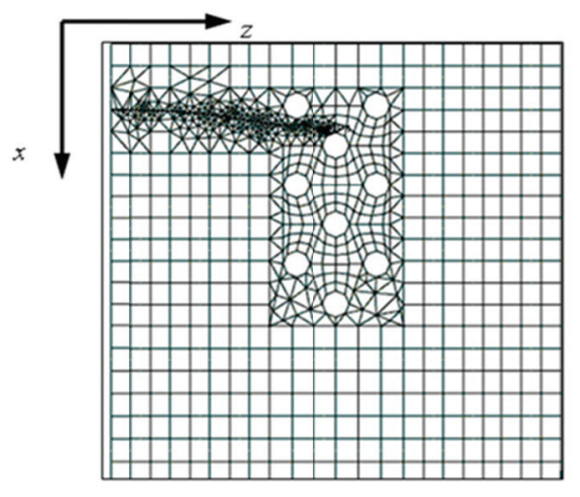

(a)

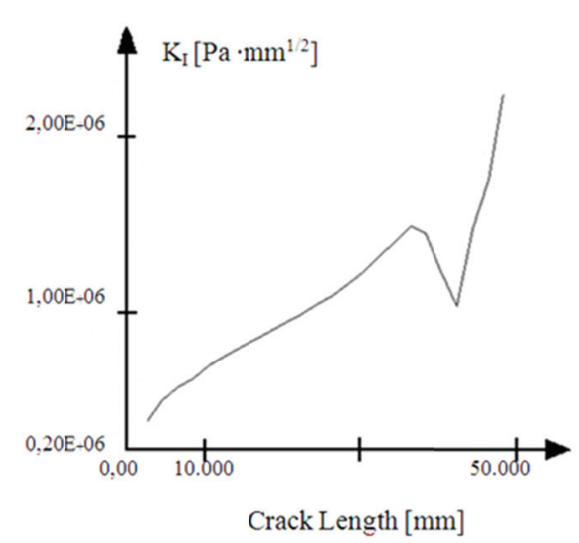

(b)

Figure 4: (a) Crown fracture propagation with a quincuncial circular crack arrester arrangement. (b) Plot of $K_{\text {ID }}$ vs. crack length.

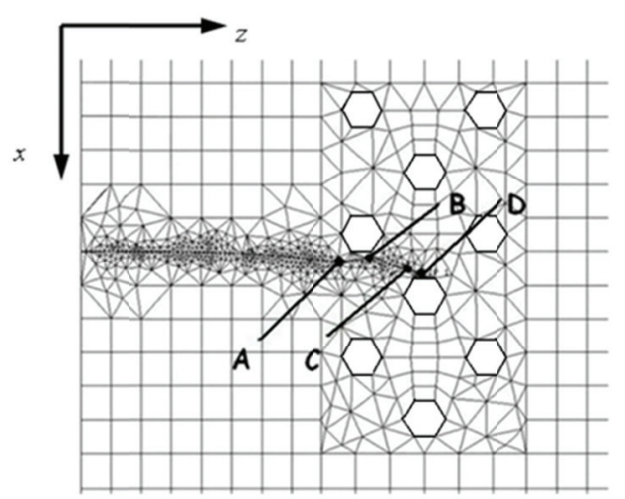

(a)

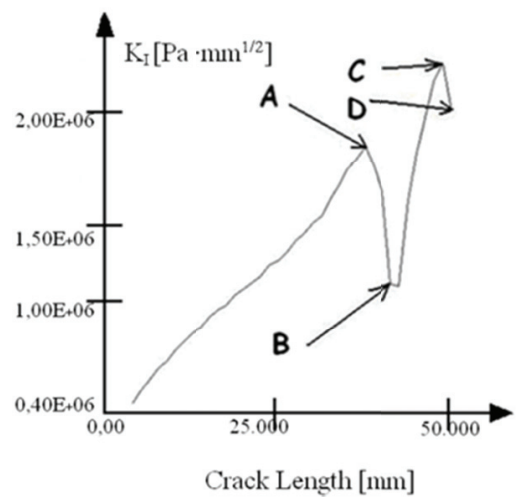

(b)

Figure 5: (a) Crown fracture propagation with a quincuncial hexagonal crack arrester arrangement. (b) Plot of $K_{I D}$ vs. crack length.

\section{DISCUSSION AND CONCLUSION}

he simulations show the effectiveness of these arresters to reduce substantially the crack driving force. This means that, to increase spatial variability helps to stabilize the slope, eventually splitting a major event into smaller, independent avalanches. So, we can suppose that the use of crack arresters is a first step towards a new idea for active avalanche protection. Usually, the long term control structures for snow avalanches in the upper zones prevent avalanches from triggering, but it is not so infrequent in big slopes that fracture in the crown can bypass the protections, due to Mode II propagation in the weak layer. Thanks to the snow crack arresters, we put forward here a new philosophy for the use of artificial discontinuities (void) distributed along the snow slope area: the target is to split a large avalanche slab into smaller slabs, causing small avalanches to propagate with less catastrophic effects.

The idea of the implementation of snow crack arresters arises from three in situ observations. The first is the analysis of the trees as natural arresters: the tree slows the flow of snow avalanches and prevents the release of avalanches thanks to the stability of the snowpack. Moreover the perimeter of the forest is a natural obstacle for the fracture in the snowpack: stopping its propagation inside of the wood, the crack is headed downhill. The second observation comes from the 
following statement: spontaneous crown fractures follow the same path. This is due to the morphology and the topography of the slope: the concave and convex ripples of the slope induce tension and compression zone inside the snowpack [13]. Studying the methods of defence against avalanches, we have identified two typologies of structures: (i) the wind deflectors with a cross shape (Fig. 6) in the ridge of the avalanche basin and (ii) the snow-grippers (Fig. 7) with a triangular shape inside the snowpack of the release area $[14,15]$. Obviously, these defence structures must be adapted to work as a crack arresters.

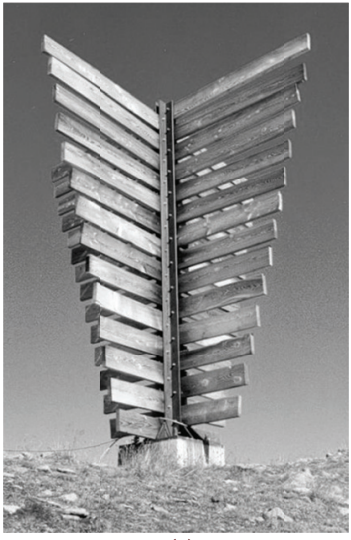

(a)

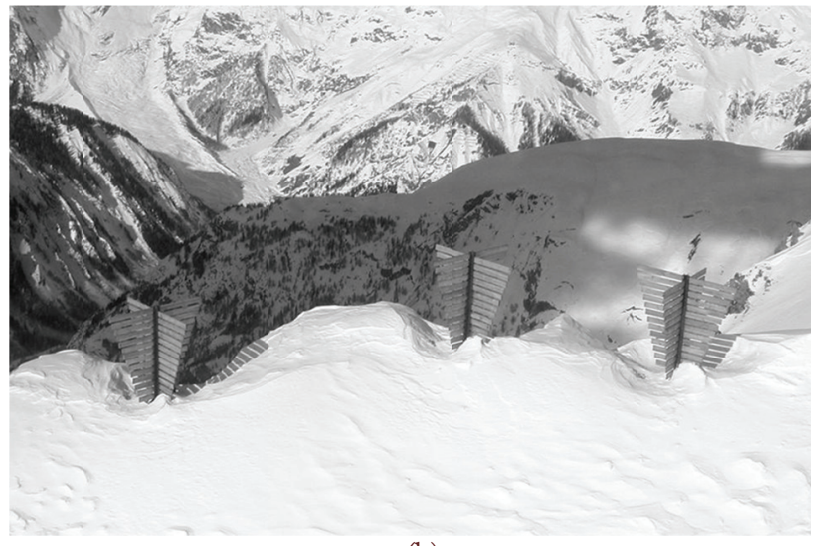

(b)

Figure 6: (a) Wind deflector with a cross shape (Photo by Frigo, 2003).

(b) Wind deflectors on the ridge of Lavancher - Morgex (AO) - basin (Photo by Ceriani, 2000).

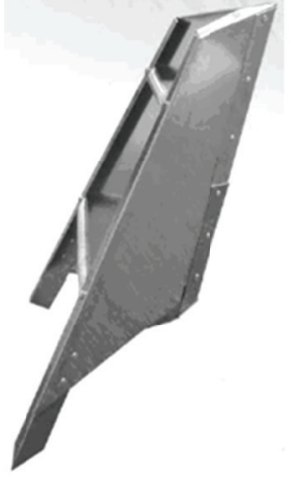

(a)

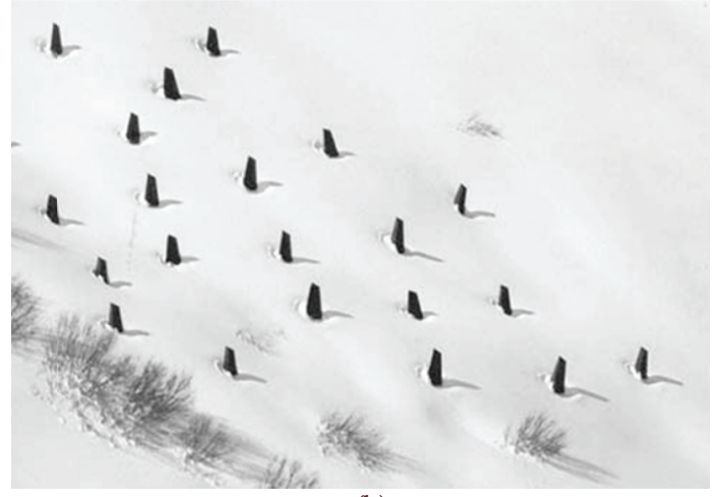

(b)

Figure 7: (a) Snow-gripper element. (b) Example of release area of the avalanche basin protected by Snow-grippers (www.incofil.com).

In conclusion, considering the snowpack as a linear-elastic plate (2D problem), the Mode I crown fracture after complete propagation of a weak layer cracking has been considered. The path of the crack has been investigated by means of numerical investigations in continuous (natural) and discontinuous (equipped with a different shapes and geometries of voids) snowpacks. The use of crack arresters is a first step towards a new idea for active avalanche protection. These preliminary results testify the effectiveness of the active crack arrest concept for dry snow avalanches. Obviously, further investigation taking into account directly Mode II arrest on the weak plane and the cohesive nature of snow is needed before definite conclusions will be drawn.

\section{ACKNOWLEDGMENTS}

$\mathrm{T}$ he financial support provided by Progetto Strategico RISKNAT - Obiettivo cooperazione territoriale europea Italia/Francia (Alpi 2007-2013) is gratefully acknowledged. The research activity is funded by grant co-supported by Regione Piemonte and Italian Ministry of Work and Social Security. 


\section{REFERENCES}

[1] D. M. McClung, J. Geophys. Res. 84(B7) (1979) 3519.

[2] B. Chiaia, P. Cornetti, B. Frigo, Cold Reg. Sci. Technol. 53 (2008) 170-178.

[3] P. Wawrzynek, A. Ingraffea, FRANC 2D - A two dimensional crack propagation simulator, User's Guide - Version 3.1, Cornell University (1993).

[4] K. Kronholm, K. W. Birkeland, Geophysical Research Letters, 32 (2005) L19504.

[5] B. Chiaia, B. Frigo, Journal of Statistical Mechanics: Theory and Experiment, (2009) P02056.

[6] T. L. Anderson, Fracture Mechanics Fundamentals and Applications, Second Edition, CRC Press (1995).

[7] J. B. Jamieson, C. D. Johnston, Canadian Geotechnical Journal, 29 (1992) 61.

[8] D. Broek, Elementary Engineering Fracture Mechanics, Martinus Nijhoff Publishers (1986).

[9] J. Schweizer, Cold Reg. Sci. Technol., 30 (1999) 43.

[10] P. M. B.Föhn, C. Camponovo, G. Krüsi, Annals of Glaciology, 26 (1998) 1.

[11] B. Jamieson, C.D. Johnston, Annals of Glaciology, 32 (2001) 59.

[12] H. O. K. Kirchner, G. Michot, J. Schweizer, Scripta Materialia, 46 (2002) 425.

[13] D. M. McClung, P. Schaerer, The Avalanche Handbook, The Mountaineers Book, Seattle WA, USA (1993).

[14] F. Sivardière, Neige et Avalanches (ANENA), (2004) 107.

[15] R. Fromm, L. Rammer, Sperimentazione snowgripper sullo Schmittenhöhe. Scheda tecnica Snowgripper (2003). 